\title{
Individual seasonality index of rainfall regimes in Greece
}

\author{
I. Livada, D. N. Asimakopoulos* \\ University of Athens, Physics Department, Section of Applied Physics, Laboratory of Meteorology, Panepistimiopolis, \\ Building Physics-5, Athens, Greece
}

\begin{abstract}
The study of rainfall seasonality in different geographical areas in Greece using an individual seasonality index was the purpose of the present work. The correlation of the seasonality index $(\overline{\mathrm{SI}}$, sum of the absolute deviation of mean monthly rainfall from the overall monthly mean divided by the mean annual rainfall) with the mean individual seasonality index $\left(\overline{\mathrm{SI}}_{i}\right.$ average of $\mathrm{SI}_{i}$ for each year i) was initially determined. A regression analysis of SI with geographical latitude resulted in a statistically significant inverse linear correlation. The time series trend of the $\mathrm{SI}_{i}$ was examined to verify that no significant change in rainfall seasonality occurred.
\end{abstract}

KEY WORDS: Seasonality index $\cdot$ Individual seasonality index $\cdot$ Rainfall distribution

\section{INTRODUCTION}

In recent years, the study of rainfall characteristics has attracted attention, especially because extreme weather conditions and possible climatic changes have been observed. Rainfall seasonality is a complex concept which incorporates a number of independent components (Walsh \& Lawler 1981). Seasonality assesses the seasonal contrasts in rainfall amounts, and not dryness or wetness in an absolute sense. A comparison of the monthly rainfall distributions of different regions can be made by quantification of rainfall regimes. Ramage (1971), Jackson (1977) and Nieuwolt (1977) describe rainfall seasonality in qualitative terms. First attempts to quantify rainfall regimes were made in the past by Ayoade (1970), Markham (1970) and Nieuwolt (1974). Walsh \& Lawler (1981) proposed a modified index for relative rainfall seasonality, which had been previously defined by Ayoade (1970). Barry \& Perry (1973) reported that it is possible to define regions with similar precipitation patterns by seasonality indices estimated using harmonic analysis. Lau \& Sheu (1988) applied harmonic analysis on the monthly value in rainfall amounts and defined the amplitude of the first harmonic, which covers 1 wave over the whole period, as the seasonality index. For the definition of relative rainfall seasonality in Africa, Hulme (1992) considered the standardized amplitude of the first harmonic that refers to the annual cycle of rainfall.

Harmonic analysis in precipitation climatology was also used in later studies to definite climatological regions in Turkey by Kadioğlu et al. (1999) and in Jordan by Tarawneh \& Kadioğlu (2003). More recently, Kanellopoulou (2002) indicated that the Greek area can be divided into 4 sub-regions using the seasonality index $(\overline{\mathrm{SI}})$, which is calculated from mean monthly rainfall data.

The spatial and temporal rainfall distribution in Greece varies greatly. Mean annual rainfall amounts are especially small (about $350 \mathrm{~mm}$ ) in the eastern regions of central and southern Greece, while in western Greece and in the mountainous areas of central and northern Greece, they exceed $2000 \mathrm{~mm}$.

Based on a network of 150 rain gauge stations from which the most representative are shown in Fig. 1, and a map (Mariolopoulos \& Karapiperis 1955) of the mean annual contours of rainfall amounts (Fig. 2) the existing variations were determined. The greater rainfall amounts are measured during the autumn and winter, while during the summer rainfall occurs only in the northern part of Greece and mainly on the highlands. 


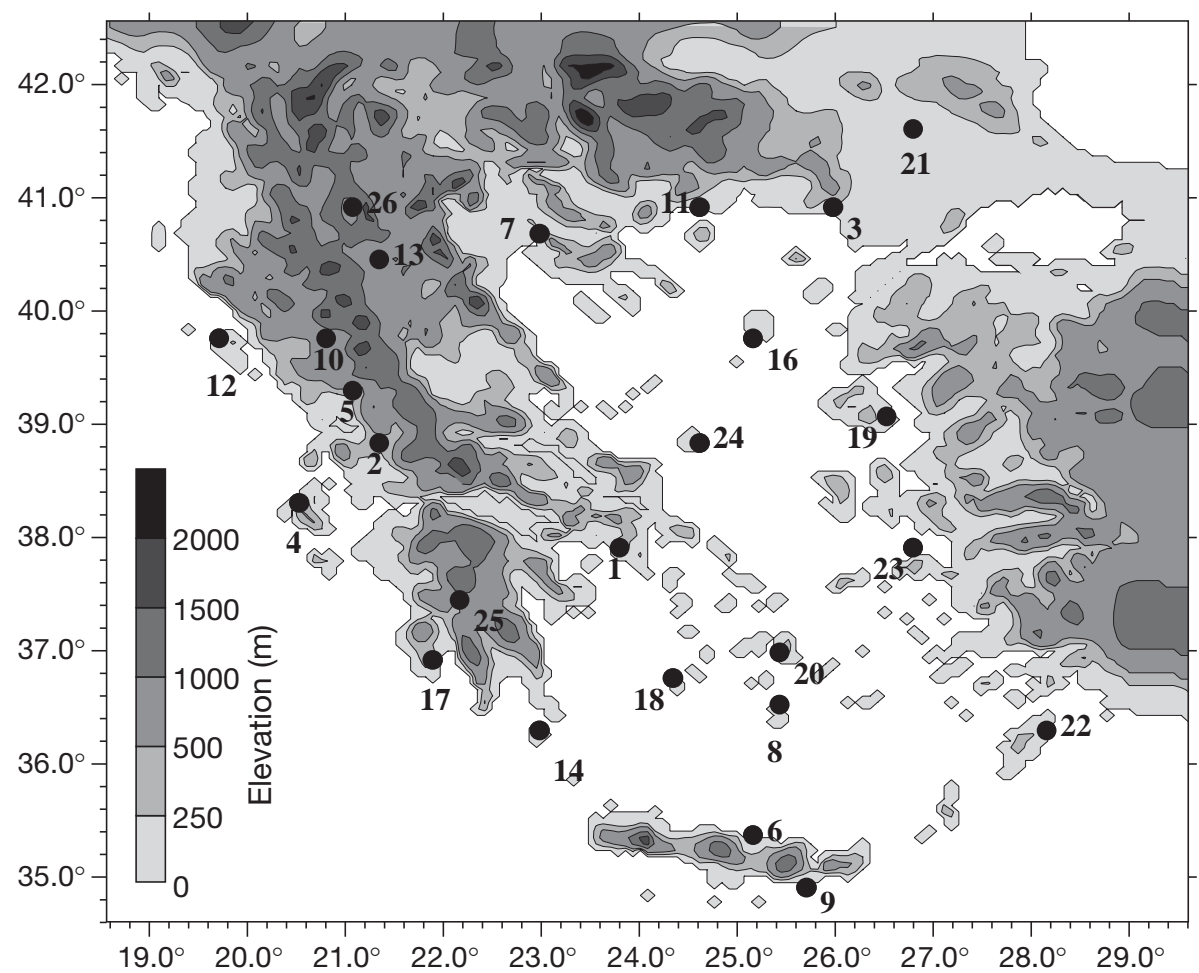

Fig. 1. Map of Greece with the numbered stations used to definite the mean individual seasonality index $\left(\overline{\mathrm{SI}_{i}}\right)$
From the above network a total of 26 stations which were considered to be the most representative (Table 1) were examined. The existing rainfall data correspond to the period 1950 to 2000 (except for data from the Orestias station, Stn 21, located in the NE part of Greece, where a 41 yr data set was available). Missing data from other stations, which corresponded to $<5 \%$ of each data set, were filled in by interpolation from adjacent stations.

The present study focuses mainly on the individual seasonality index $\left(\mathrm{SI}_{i}\right)$, which provides information about the interannual variations in seasonality, whereas the $\overline{\mathrm{SI}}$ estimates only the mean seasonality over the length of the available records. Thus, temporal variation in seasonality will be investigated via the mean individual seasonality index $\left(\mathrm{SI}_{i}\right)$. A correlation between the 2 indices was found and the spatial distribution of the $\overline{\mathrm{SI}}$, as well as the relation of this index to geographical latitude and proximity to the sea, were investigated.

\section{QUANTIFICATION OF RAINFALL REGIMES OVER GREECE}

Relative seasonality of rainfall can be expressed by the coefficient of variation $(\mathrm{CV})$ of monthly rainfall amounts throughout the year. This statisti-

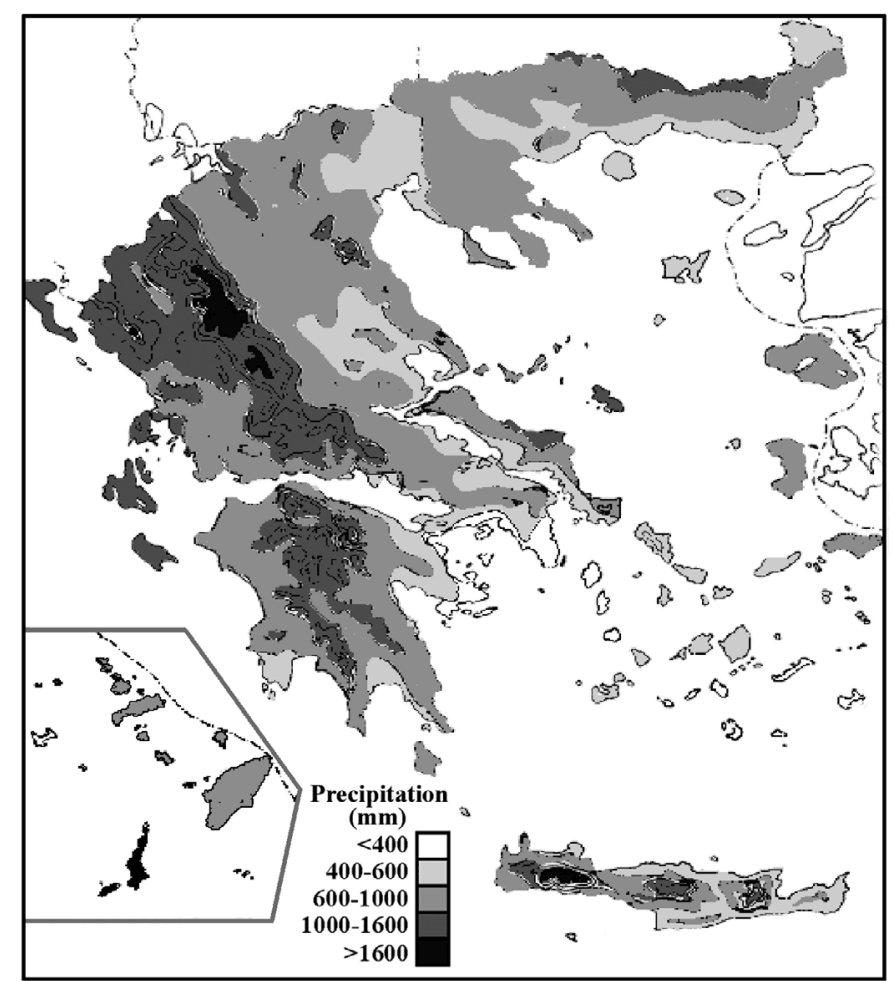

Fig. 2. Contours of average annual rainfall amounts over the Greek territory according to Mariolopoulos \& Karapiperis (1955) 
Table 1. Mean seasonal and annual rainfall amounts for 26 meteorological stations throughout Greece for the time period 1950 to 2000

\begin{tabular}{|c|c|c|c|c|c|c|}
\hline \multicolumn{2}{|c|}{ Station } & \multirow[t]{2}{*}{ Spring } & \multirow[t]{2}{*}{ Summer } & \multirow[t]{2}{*}{ Autumn } & \multirow{2}{*}{ Winter } & \multirow[t]{2}{*}{ Annual } \\
\hline 1. & Athens & & & & & \\
\hline & (Nat. Observatory) & 93.9 & 18.7 & 119.0 & 154.6 & 386.1 \\
\hline 2. & Agrinio & 178.8 & 54.1 & 309.6 & 388.6 & 931.0 \\
\hline 3. & Alexandroupoli & 121.1 & 59.7 & 164.0 & 204.2 & 548.7 \\
\hline 4. & Argostoli & 164.6 & 26.3 & 316.2 & 424.5 & 931.6 \\
\hline 5. & Arta & 230.9 & 53.1 & 367.3 & 477.1 & 1128.4 \\
\hline 6. & Iraklio & 99.4 & 4.3 & 138.2 & 233.0 & 475.9 \\
\hline 7. & Thessaloniki & 114.9 & 71.9 & 126.7 & 120.2 & 433.8 \\
\hline 8. & Thira & 80.9 & 1.9 & 67.9 & 183.1 & 333.8 \\
\hline 9. & Ierapetra & 78.3 & 2.0 & 113.4 & 289.6 & 483.2 \\
\hline 10. & Ioannina & 240.7 & 100.9 & 337.6 & 426.8 & 1106.1 \\
\hline 11. & Kavala & 124.8 & 85.0 & 142.0 & 185.3 & 537.1 \\
\hline 12. & Kerkyra & 196.7 & 39.5 & 421.1 & 462.1 & 1119.4 \\
\hline 13. & Kozani & 137.3 & 105.5 & 148.8 & 117.9 & 509.5 \\
\hline 14. & Kythira & 93.3 & 6.2 & 158.1 & 282.3 & 539.9 \\
\hline 15. & Larissa & 113.0 & 56.2 & 143.9 & 125.2 & 438.3 \\
\hline 16. & Lemnos & 105.7 & 35.9 & 131.3 & 213.2 & 486.1 \\
\hline 17. & Methoni & 121.3 & 10.3 & 245.2 & 335.9 & 712.7 \\
\hline 18. & Milos & 86.9 & 5.0 & 115.7 & 212.5 & 420.1 \\
\hline 19. & Mytilini & 140.8 & 11.1 & 154.3 & 351.8 & 658.0 \\
\hline 20. & Naxos & 76.0 & 4.8 & 94.3 & 192.6 & 367.7 \\
\hline 21. & Orestias $^{\mathrm{a}}$ & 151.1 & 96.9 & 161.8 & 194.3 & 604.1 \\
\hline 22. & Rhodos & 130.9 & 2.4 & 169.3 & 425.0 & 727.6 \\
\hline 23. & Samos & 167.4 & 5.7 & 171.5 & 438.4 & 783.0 \\
\hline 24. & Skyros & 94.1 & 17.9 & 114.3 & 209.4 & 435.7 \\
\hline & Tripoli & 173.7 & 61.4 & 216.2 & 337.6 & 788.8 \\
\hline 26. & Florina & 175.1 & 101.7 & 199.8 & 192.6 & 663.1 \\
\hline
\end{tabular}

The mean $\overline{\mathrm{SI}}_{i}$ is the average of $\mathrm{SI}_{i}$ for each year $i$ and it is defined as the sum of the absolute deviation of monthly rainfall from the mean monthly rainfall of year $i$ divided by the annual rainfall $\left(R_{i}\right)$ of year $i$.

The $\overline{\mathrm{SI}}$ for the Greek area was first used by Kanellopoulou (2002), based on a 30 yr rainfall data set from 30 meteorological stations. The result was the classification of Greek territory into 4 zones, ranging from a rainfall regime which is 'equable with a definite wetter season to a regime which is 'markedly seasonal with a long drier season'.

The present study estimates the $\overline{\mathrm{SI}}$ for a total of 150 stations, which are well distributed over the Greek territory. The available data sets exceeded, in some cases, 50 yr. A first conclusion of this work indicated the existence of an additional zone in the northern part of Greece, one fitting the classification 'very equable', and allowed the definition of a statistically significant negative linear correlation $(r=-0.838)$ between the $\overline{\text { SI }}$ values and geographical latitude $\varphi$ (Fig. 3). In the case of the greater Athens area (16 rain gauge), the $\overline{\mathrm{SI}}$ index varied between 'rather seasonal with a short drier season' and 'seasonal'. Deviations in the $\overline{\mathrm{SI}}$ for such small distances was

cal parameter indicates seasonal variations in rainfall amounts. Nevertheless, it is important not only to identify but also to characterize these seasonal variations, and those seasonality indices were used in the present study.

The $\overline{\mathrm{SI}}$ and the $\overline{\mathrm{SI}_{i}}$ proposed by Walsh \& Lawler (1981) were applied in order to quantify the annual rainfall regimes. These indices can show differences in relative seasonality even in areas with 2 or 3 rainfall peaks throughout the year. The $\overline{\mathrm{SI}}$ is defined as the sum of the absolute deviation of mean monthly rainfall from the overall monthly mean divided by the mean annual rainfall

$$
\overline{\mathrm{SI}}=\frac{1}{\bar{R}} \sum_{n=1}^{n=12}\left|\bar{x}_{n}-\frac{\bar{R}}{12}\right|
$$

where $\bar{x}_{n}$ indicates the mean rainfall of month $n$ and $\bar{R}$ the mean annual rainfall.

This index varies from zero (when all months share the same amount of rainfall), to 1.83 (when all rainfall incidences occur in a single month). A classification of rainfall regimes based on $\overline{\mathrm{SI}}$ values is shown in Table 2 . attributed more to proximity to the sea (linear correlation coefficient $r=-0.359$ ) than to the altitude of the station. Similar results $(\mathrm{r}=-0.446)$ were also obtained when 15 coastal and lower elevation inland meteorological stations in the Macedonia area (north-central Greek mainland) were used. As a result, the closer the station was to the sea, the larger the $\overline{\mathrm{SI}}$ value became. Moreover, the correlation between the $\overline{\text { SI }}$ values and the CV of the mean monthly rainfall amounts was statistically significant $(\mathrm{r}=0.98)$.

Table 2. Classification of seasonality index ( $\overline{\mathrm{SI}})$ according to Walsh \& Lawler (1981). See text for explanation of $\overline{\text { SI }}$ values

\begin{tabular}{|lc|}
\hline Rainfall regime & $\overline{\mathrm{SI}}$ \\
\hline Very equable & $\leq 0.19$ \\
Equable with a definite wetter season & $0.20-0.39$ \\
Rather seasonal with a short drier season & $0.4-0.59$ \\
Seasonal & $0.60-0.79$ \\
Markedly seasonal with a long drier season & $0.80-0.99$ \\
Most rain in 3 mo or less & $1.00-1.19$ \\
Extreme, almost all rain in 1 to 2 mo & $\geq 1.20$ \\
\hline
\end{tabular}




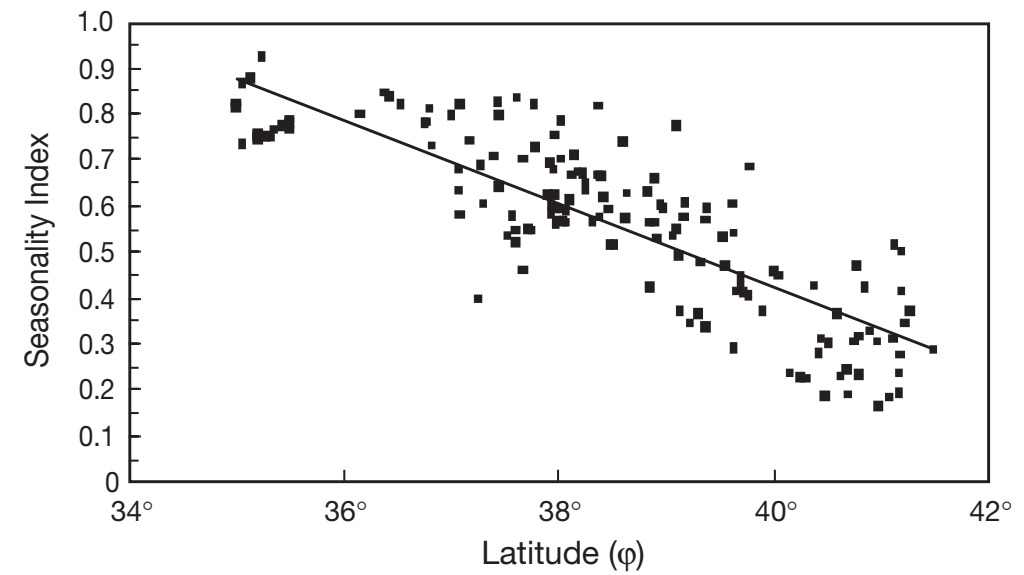

Fig. 3. Scatter diagram and linear regression line of seasonality index $\overline{\mathrm{SI}}$ with regard to latitude $(\varphi)$

\section{SEASONALITY INDEX $(\overline{\mathrm{SI}})$ AND MEAN INDIVIDUAL SEASONALITY INDEX $\left(\overline{\mathbf{S I}_{i}}\right)$}

According to Walsh \& Lawler (1981), the $\overline{\mathrm{SI}}$ is underestimated when mean values are used. This problem can be overcome by obtaining the mean $\overline{\mathrm{SI}_{i}}$ from averaged $\mathrm{SI}_{i}$ individual year values, where $i$ refers to the value derived from the individual year data.

Table 3. The linear correlation coefficient, $\mathrm{r}_{\text {, }}$ between $\overline{\mathrm{SI}_{i}}$ and $\overline{\mathrm{SI}}$ values, $\overline{\mathrm{SI}_{i}}$ and $\overline{\mathrm{SI}}$ values, and the $\overline{\mathrm{SI}} / \overline{\mathrm{SI}}_{i}$ ratios for the 26 meteorological stations examined

\begin{tabular}{|c|c|c|c|c|}
\hline Station & $\mathrm{r}$ & $\overline{\mathrm{SI}_{i}}$ & $\overline{\mathrm{SI}}$ & $\overline{\mathrm{SI}} / \overline{\mathrm{SI}_{i}}$ \\
\hline \multicolumn{5}{|l|}{ 1. Athens } \\
\hline (Nat. Observatory) & 0.838 & 0.831 & 0.594 & 0.715 \\
\hline 2. Agrinio & 0.789 & 0.742 & 0.572 & 0.771 \\
\hline 3. Alexandroupoli & 0.816 & 0.704 & 0.421 & 0.598 \\
\hline 4. Argostoli & 0.793 & 0.802 & 0.673 & 0.839 \\
\hline 5. Arta & 0.785 & 0.751 & 0.574 & 0.764 \\
\hline 6. Iraklio & 0.725 & 0.934 & 0.747 & 0.800 \\
\hline 7. Thessaloniki & 0.869 & 0.612 & 0.231 & 0.377 \\
\hline 8. Thira & 0.825 & 1.004 & 0.836 & 0.833 \\
\hline 9. Ierapetra & 0.746 & 1.005 & 0.831 & 0.827 \\
\hline 10. Ioannina & 0.836 & 0.636 & 0.446 & 0.701 \\
\hline 11. Kavala & 0.831 & 0.638 & 0.327 & 0.513 \\
\hline 12. Kerkyra & 0.796 & 0.781 & 0.604 & 0.773 \\
\hline 13. Kozani & 0.899 & 0.585 & 0.224 & 0.383 \\
\hline 14. Kythira & 0.553 & 0.938 & 0.800 & 0.853 \\
\hline 15. Larissa & 0.845 & 0.651 & 0.290 & 0.445 \\
\hline 16. Lemnos & 0.734 & 0.798 & 0.539 & 0.675 \\
\hline 17. Methoni & 0.701 & 0.846 & 0.731 & 0.864 \\
\hline 18. Milos & 0.737 & 0.964 & 0.779 & 0.808 \\
\hline 19. Mytilini & 0.662 & 0.921 & 0.772 & 0.838 \\
\hline 20. Naxos & 0.832 & 0.972 & 0.796 & 0.819 \\
\hline 21. Orestias & 0.738 & 0.615 & 0.286 & 0.465 \\
\hline 22. Rhodos & 0.760 & 0.990 & 0.845 & 0.854 \\
\hline 23. Samos & 0.671 & 0.965 & 0.819 & 0.849 \\
\hline 24. Skyros & 0.827 & 0.846 & 0.657 & 0.777 \\
\hline 25. Tripoli & 0.847 & 0.712 & 0.534 & 0.750 \\
\hline 26. Florina & 0.907 & 0.544 & 0.224 & 0.412 \\
\hline
\end{tabular}

For the estimation of $\mathrm{SI}_{i}$, a total of 26 meteorological stations were studied (Table 1). These stations were carefully selected because they provided a longterm history of reliable data and in addition were representative of the stations in the investigation area. The $\overline{\mathrm{SI}}$ values at these stations varied between 0.224 and 0.845 . Table 3 shows that $\overline{\mathrm{SI}_{i}}$ values are significantly higher than the $\overline{\mathrm{SI}}$ values. This is in agreement with Walsh \& Lawler (1981), whose results are based on similar studies in various regions of the world.

In order to assess the degree of variability in rainfall regimes the $\overline{\mathrm{SI}} / \overline{\mathrm{SI}_{i}}$ ratio was examined (Table 3 ). When the $\overline{\mathrm{SI}} / \overline{\mathrm{SI}_{i}}$ ratio is high, the month of maximum rainfall occurs over a small spread of months and the range of $\overline{\mathrm{SI}_{i}}$ values is also small. This leads to a high repeatability of the mean rainfall regime and vice versa. Fig. 4 illustrates these points for the 2 stations with the maximum and minimum $\overline{\mathrm{SI}} / \overline{\mathrm{SI}_{i}}$ values. In Methoni, a coastal station in SW Greece with an elevation of $55 \mathrm{~m}$, the maximum rainfall occurs in a short time period (October to February) and the $\overline{\mathrm{SI}} / \overline{\mathrm{SI}_{i}}$ ratio is estimated to be 0.864 . In contrast, in Kozani $\left(\overline{\mathrm{SI}} / \overline{\mathrm{SI}_{i}}=\right.$ 0.383) rainfall occurs in a wide variety of months, showing a relative lack of reliability in rainfall and also in the appearance and amount of rainfall. The Kozani station is a continental station situated in the northern part of the Greece with an elevation of 625 m. Fig. 5

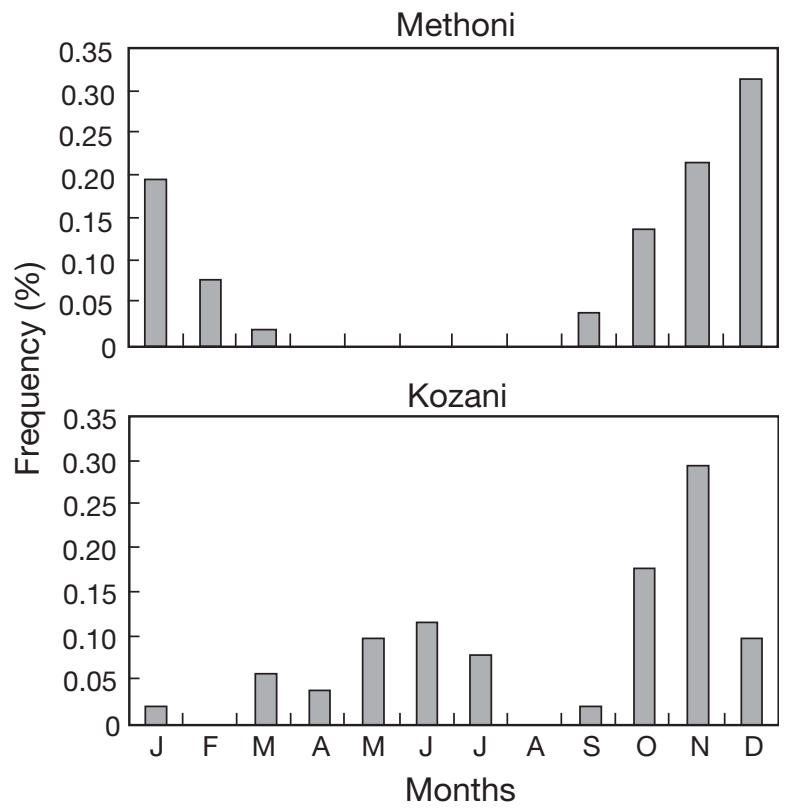

Fig. 4. Maximum monthly rainfall (\%) at the Methoni and Kozani stations 


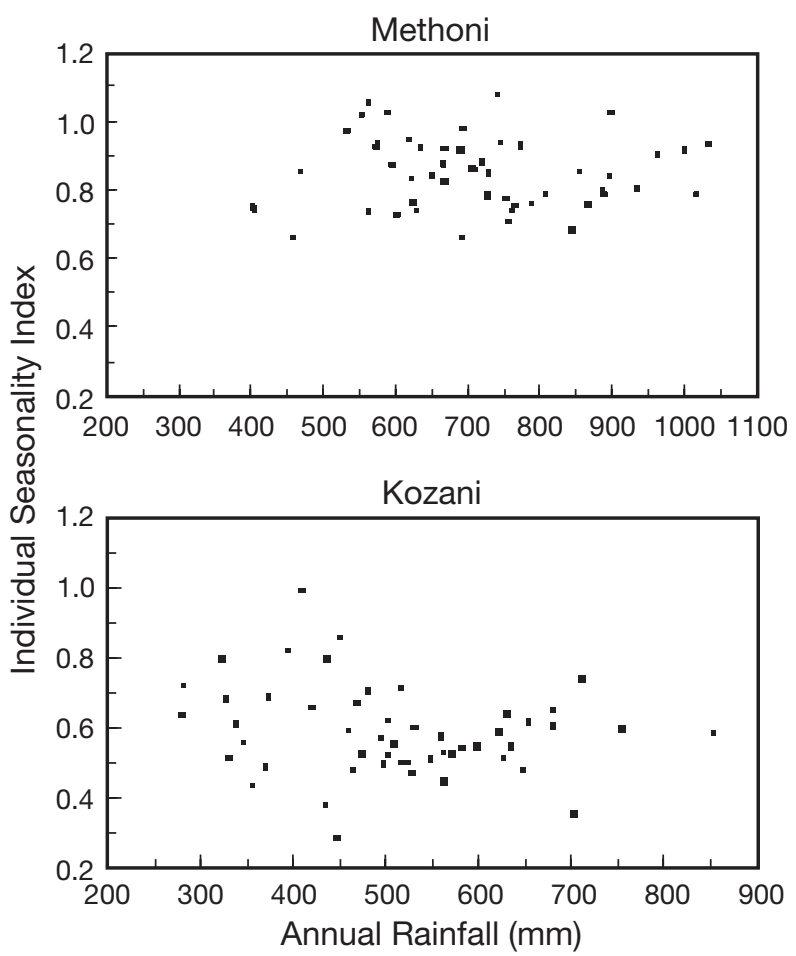

Fig. 5. Scatter diagram of annual rainfall with regard to individual seasonality index values

presents a scatter diagram of the $\mathrm{SI}_{i}$ with regard to annual rainfall for the 2 stations. As seen in Fig. 5, there is no relationship between annual rainfall and seasonality. Also, no correlation was observed between annual rainfall values and the corresponding $\mathrm{SI}_{i}$ values. This can be explained by the fact that the $\mathrm{SI}_{i}$ index values depict only the interannual variability of rainfall. This is also observed by the statistically significant logarithmic correlation coefficient $(\mathrm{r}=0.55$ to 0.91) between annual rainfall CV and the corresponding $\mathrm{SI}_{i}$ index.

Considering that the $\mathrm{SI}_{i}$ gives more information about rainfall seasonality than the $\overline{\mathrm{SI}}$ index, the relationship between $\overline{\mathrm{SI}_{i}}$ and $\overline{\mathrm{SI}}$ has been examined. A statistically significant correlation $(r=0.951)$ between $\overline{\mathrm{SI}}$ and $\overline{\mathrm{SI}}_{i}$ values was found (Fig. 6), which is expressed by the formula:

$$
\overline{\mathrm{SI}}_{i}=0.4755 \mathrm{e}^{0.8625 \overline{\mathrm{SI}}}
$$

The above relationship is not of general use, having failed to apply to the Walsh \& Lawler (1981) data. Thus, it was concluded that the constants must be determined for each site.

In order to study in more detail the variation in the $\mathrm{SI}_{i}$ index over Greek territory, the $\mathrm{SI}_{i}$ values for each year were estimated. Fig. 7 shows the distribution of $\mathrm{SI}_{i}$ values illustrated with boxplots for the total number of

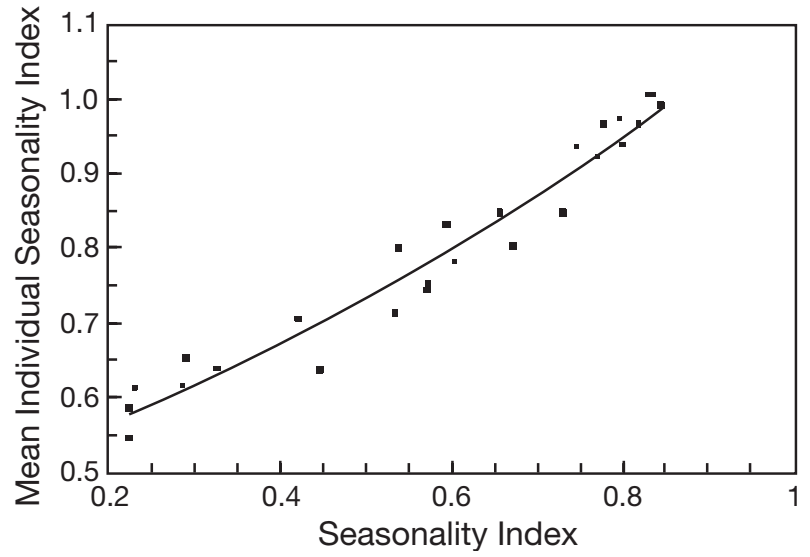

Fig. 6. Scatter diagram with the linear regression line of the seasonality index $\overline{\mathrm{SI}}$ with regard to the mean individual seasonality index $\left(\overline{\mathrm{SI}_{i}}\right)$

stations. In the northern part of Greece the $\overline{\mathrm{SI}}_{i}$ values are generally smaller in comparison with the other 2 regions, while the larger values are observed in the southern region. In addition, the estimated deviations in each region seem to local phenomena.

Based on the classification given in Table 2, the $\overline{\mathrm{SI}_{i}}$ values range between 'rather seasonal with a short drier season' and 'Most rain in 3 mo or less', which seems to be more realistic for the Hellenic region. As for the extreme $\mathrm{SI}_{i}$ values, these vary from 'equable with a definite wetter season' to 'extreme, almost all rain in 1 to $2 \mathrm{mo}^{\prime}$. Thus, considering either $\overline{\mathrm{SI}}_{i}$ or extreme $\mathrm{SI}_{i}$ values, detailed information can be acquired in comparison with the $\overline{\mathrm{SI}}$ index.

The total number of stations were categorized into Northern, Central and Southern taking into account the statistically significant linear correlation between

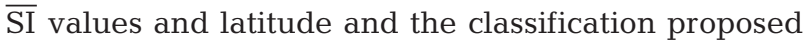
by Loukas et al. (2001). The similar $\overline{\text { SI }}$ values observed between the Central and Southern stations (Stns 23 and 20 and Stns 6, 14, 18, 22, 8 and 9, respectively) are attributed to the small number of thunderstorms that occur during the summer period (May to September) in the above stations. Moreover, Stn 20 lies near the border between the central and southern zone. The ratio of the number of thunderstorms during the summer period to the total number of thunderstorms during the year shows a statistically significant negative linear correlation $(\mathrm{r}=-0.84)$ with the mean $\overline{\mathrm{SI}}_{i}$. Considering that summer thunderstorms in Greece have a local character, it is possible to have high $\overline{\mathrm{SI}}_{i}$ values in some northern locations where summer thunderstorms do not occur (i.e. the Mytilini station, Stn 19). Because of this local character, the attempt to use different boundary settings from SW to NE did not provide a better grouping of stations with respect to the $\mathrm{SI}_{i}$ values. 


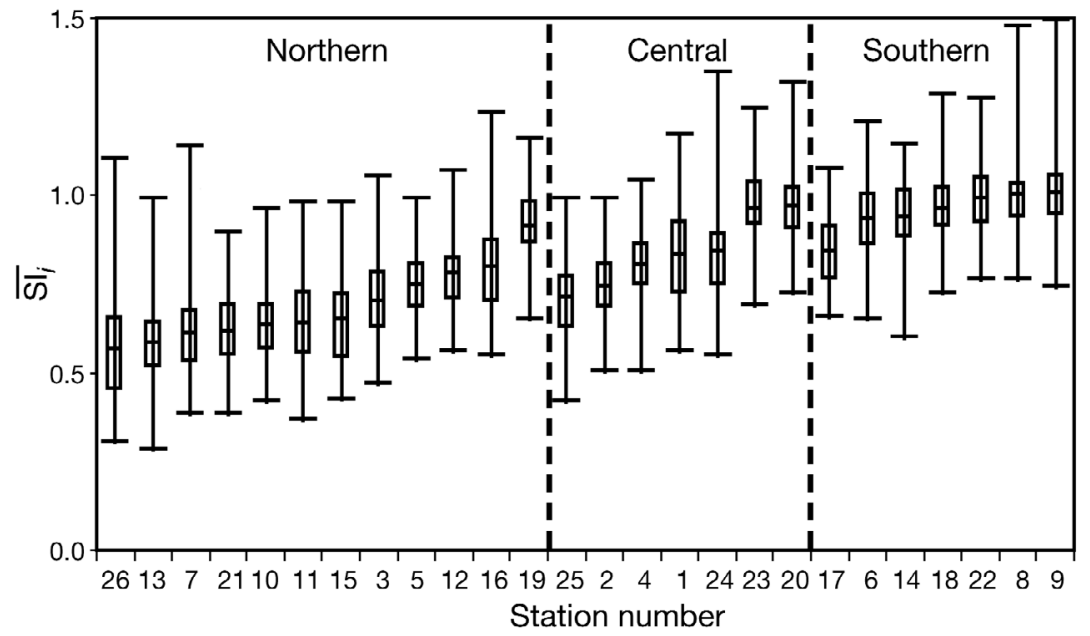

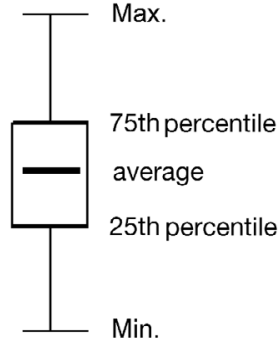

Fig. 7. Boxplots of individual seasonality index $\left(\mathrm{SI}_{i}\right)$ values for the 26 stations divided geographically into northern, central and southern stations

\section{TIME SERIES ANALYSIS OF $\mathrm{SI}_{i}$}

Rainfall regimes over the Greek area are characterized by a marked dry season and a wet winter period. A change in the annual rainfall amounts (Goudie 1977, Hatfield et al. 1999) or in seasonality is possible when the duration of the wet or dry season changes (Stoddart \& Walsh 1975, Stoddart 1979). To investigate trends in the time series of the $\mathrm{SI}_{i}$ index, the Spearman statistical test of tendency was applied (Sneyers 1975, Lioki-Livada \& Asimakopoulos 2004). Thus, the correlation coefficient, $\mathrm{r}_{\mathrm{S}}$, between $i$ and $k_{n}$ was calculated:

$$
\mathrm{r}_{\mathrm{S}}=1-6 \frac{\sum_{n=1}^{N}\left(k_{n}-i\right)^{2}}{N\left(N^{2}-1\right)}
$$

where $i$ is the order of each value in the time series, $k_{n}$ is the order of each value in the increasing tabulation class of the $\mathrm{SI}_{i}$ index and $N$ is the sample magnitude.

The distribution of $r_{S}$ follows asymptotically the normal distribution with mean $\mathrm{E}\left(\mathrm{r}_{\mathrm{S}}\right)=0$ and $\operatorname{var}\left(\mathrm{r}_{\mathrm{S}}\right)=$ $1 /(N-1)$ where $\mathrm{E}\left(\mathrm{r}_{\mathrm{S}}\right)$ is the mean value of the normal distribution of $r_{S}$ and var $\left(r_{S}\right)$ is the variance of the normal distribution of $r_{S}$. The probability $\alpha_{1}=P\left(|u|>\mid u\left(r_{S} \mid\right)\right.$ is estimated at a significance level of $\alpha_{0}=0.05$, where $\alpha$ is an expression of the probability $\alpha_{1}$ in order to test the null hypothesis, $u\left(r_{S}\right)=r_{S} \sqrt{N-1}$ is a value of the distribution of $r_{S}$, and $u$ is a value of the normal distribution of the population of $\mathrm{r}_{\mathrm{S}}$. The null hypothesis $\left(H_{0}\right.$ : no tendency) is accepted if $\alpha_{1}>\alpha_{0}$ (Sneyers 1975).

The $r_{S}$ values of Spearman's statistical test for these stations are given in Table 4 . In all cases, the test has shown that there is no statistically significant trend in the $\mathrm{SI}_{i}$ index. Thus, there is no obvious change in the duration of the wet or dry season.

In general, it can be considered that with the application of a 10 yr low-pass filter, the time series of smoothed $\mathrm{SI}_{i}$ values can be better approached by a linear regression line. Afterwards, the least square method (Lioki-Livada \& Asimakopoulos 2004) was applied in order to study the tendency of the time series. The tendency was tested by the statistical significance of the slope $b$ of the regression line (Zar 1999). The application of a Student's $t$-test (Table 4) showed that there is no statistically significant tendency at any station at the 0.05 significance level, since all $t_{b}$ values were lower than the critical value $\left(t_{0.05}=\right.$ 2.01). The tendency analysis was not applied to the

Table 4. Spearman's statistical coefficients of tendency, $r_{\mathrm{S}}, u\left(\mathrm{r}_{\mathrm{S}}\right)$, and the $t$-test values $\left(t_{b}\right)$, for the slope of the regression line

\begin{tabular}{|lrrr|}
\hline Station & $\mathrm{r}_{\mathrm{S}}$ & $u\left(\mathrm{r}_{\mathrm{S}}\right)$ & $t_{b}$ \\
\hline 1. Athens (Nat. Observatory) & 0.147 & 1.042 & 1.073 \\
2. Agrinio & 0.108 & 0.765 & 0.699 \\
3. Alexandroupoli & 0.085 & 0.602 & 0.001 \\
4. Argostoli & 0.272 & 1.944 & 1.392 \\
5. Arta & 0.129 & 0.910 & 1.086 \\
6. Iraklio & 0.055 & 0.387 & 0.319 \\
7. Thessaloniki & 0.099 & 0.701 & 1.213 \\
8. Thira & 0.073 & 0.516 & 0.519 \\
9. Ierapetra & 0.933 & 0.656 & 0.736 \\
10. Ioannina & 0.149 & $\mathrm{a} 1.052$ & 1.168 \\
11. Kavala & -0.094 & -0.664 & -1.379 \\
12. Kerkyra & -0.043 & -0.307 & -1.145 \\
13. Kozani & 0.046 & 0.323 & 0.0001 \\
14. Kythira & 0.275 & 1.946 & 0.873 \\
15. Larissa & 0.012 & 0.085 & 0.568 \\
16. Lemnos & 0.144 & 1.015 & 0.923 \\
17. Methoni & 0.081 & 0.570 & 0.263 \\
18. Milos & 0.170 & 1.201 & 1.075 \\
19. Mytilini & -0.006 & -0.041 & -0.001 \\
20. Naxos & 0.272 & 1.926 & 1.298 \\
22. Rhodos & 0.087 & 0.618 & 0.449 \\
23. Samos & 0.178 & 1.26 & 0.996 \\
24. Skyros & 0.122 & 0.865 & 1.664 \\
25. Tripoli & 0.085 & 0.588 & 0.312 \\
26. Florina & 0.039 & 0.276 & 0.565 \\
\hline
\end{tabular}




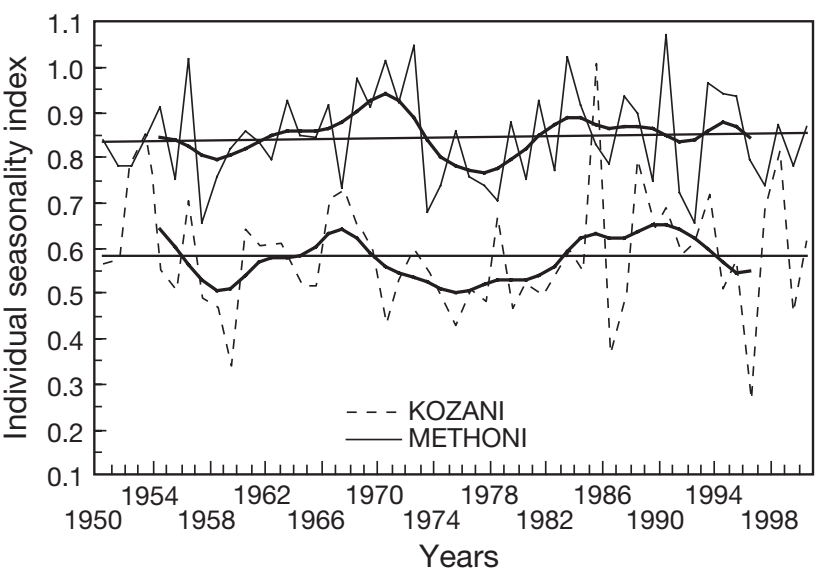

Fig. 8. Time series of the individual seasonality index $\left(\mathrm{SI}_{i}\right)$ with the corresponding $10 \mathrm{yr}$ low-pass filter and the regression lines for the Methoni and Kozani stations

Orestias station (Stn 21) due to the large amounts of missing data during the periods 1990-1993 and 1998-2000. Fig. 8 presents the time series of the $\mathrm{SI}_{i}$ in Kozani and Methoni, where this index has relatively low and high values, respectively.

\section{CONCLUSION}

The $\overline{\text { SI }}$ defined over the Greek territory was found to range between 'very equable' and 'markedly seasonal with a long drier season'. This leads to underestimated

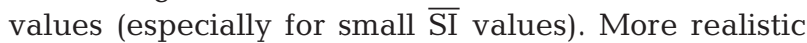
seasonality evaluations for the rainfall regimes over Greece can be made using the $\overline{\mathrm{SI}}_{i}$. It has been found that the $\overline{\mathrm{SI}}_{i}$ values vary from 0.544 to 1.005 . Between the 2 indices there is a statistically significant exponential correlation, which allows for an accurate evaluation of the $\overline{\mathrm{SI}}_{i}$ index. The equation relating the 2 indices $\left(\overline{\mathrm{SI}}\right.$ and $\left.\overline{\mathrm{SI}}_{i}\right)$ can be applied to other regions, providing that the constants are suitably determined.

Furthermore, it was found that there is a statistically significant negative linear correlation between the index values $\overline{\mathrm{SI}}$ or $\overline{\mathrm{SI}}_{i}$ and geographical latitude, while at the same time the influence of proximity to the sea on seasonality is apparent. The significant impact of summer thunderstorms on the $\overline{\mathrm{SI}}$ values, which is a regional phenomenon in Greece, does not allow a classification of Greek territory according to the rainfall seasonality index.

In addition, $\mathrm{SI}_{i}$ values very accurately depict interannual rainfall variability, indicating no statistically

Editorial responsibility: Otto Kinne, Oldendorf/Luhe, Germany significant trend. Thus, it can be concluded that the observed rainfall regimes have not changed in the last 50 years, despite the observed reduced tendency in the annual rainfall amounts.

\section{LITERATURE CITED}

Ayoade JO (1970) The seasonal incidence of rainfall. Weather 25:414-418

Barry RG, Perry AH (1973) Synoptic climatology. Methods and applications. Methueu, London

Goudie AS (1977) Environmental change. Clarendon Press, Oxford

Hammill J (1972) Seasonality of precipitation in Brazil. Rev Geografica 77:123-139

Hatfield JL,Prueger JH, Meek DW (1999) Spatial variation of rainfall over a large watershed in central Iowa. Theor Appl Climatol 64:49-60

Hulme M (1992) Rainfall changes in Africa: 1931-1960 to 1961-1990. Int J Climatol 12:685-699

Jackson IJ (1977) Climate, water and agriculture in the tropics. Longmans, London

Kadioğlu M, Ozturk N, Erdun H, Sen Z (1999) On the precipitation climatology of Turkey by harmonic analysis. Int J Climatol 19:1717-1728

Kanellopoulou EA (2002) Spatial distribution of rainfall seasonality in Greece. Weather 57:215-219

Lau KM, Sheu PJ (1988) Annual cycle, quasi-biennial oscillation and southern oscillation in global precipitation. J Geophys Res 93, D9:10975-10988

Lioki-Livada I, Asimakopoulos DN (2004) Introduction to applied statistics. Symmetria Press, Athens

Loukas A, Vasiliades L, Dalezios NR, Domenikiotis C (2001) Rainfall-frequency mapping for Greece. Phys Chem Earth (B) 26 (9):669-674

Mariolopoulos H, Karapiperis L (1955) Precipitation over Greece (a map). Athens (in Greek)

Markham CG (1970) Seasonality of precipitation in the United States. Am Assoc Am Geogr 60:593-597

Nieuwolt S (1974) Seasonal rainfall distribution in Tanzania and its cartographic representation. Erdkunde 28:186-194

Nieuwolt S (1977) Tropical climatology. Wiley, London

Ramage CS (1971) Monsoon meteorology. Academic Press, New York

Sneyers R (1975) Sur l'analyse statistique des séries d'observations. OMM(WMO) No 415 Note Technique 143:10-11

Stoddart DR, Walsh RPD (1975) Environmental variability and environmental extremes as factors in the island ecosystem. 13th Pacific Science Congress, Vancouver

Stoddart DR (1979) Long-term climatic change in the western Indian Ocean. Phil Trans R Soc Lond B 286:11-23

Tarawneh Q, Kadioğlu M (2003) An analysis of precipitation climatology in Jordan. Theor Appl Climatol 74: 123-136

Walsh RPD, Lawler DM (1981) Rainfall seasonality spatial patterns and change through time. Weather 36:201-208

Wood NL (2003) Regional climate trends in south-west England and the North Atlantic Oscillation. Weather 59:39-41

Zar JH (1999) Biostatistical analysis, 4th edn. Prentice Hall, Upper Saddle River, NJ

Submitted: December 5, 2003; Accepted: November 23, 2004 Proofs received from author(s): February 28, 2005 